\section{Improved Detection of Abnormal Glucose Tolerance in Africans: The Value of Combining Hemoglobin $\mathrm{A}_{1 \mathrm{c}}$ With Glycated Albumin}

Diabetes Care 2020;43:2607-2613 | https://doi.org/10.2337/dc20-1119

\section{OBJECTIVE}

In African-born Blacks living in America, we determined by BMI category 1) prevalence of abnormal glucose tolerance (Abnl-GT) and 2) diagnostic value and reproducibility of hemoglobin $A_{1 c}\left(H_{b A_{1 c}}\right)$, fructosamine, and glycated albumin (GA).

\section{RESEARCH DESIGN AND METHODS}

Participants ( $n=416$; male, 66\%; BMI $27.7 \pm 4.5 \mathrm{~kg} / \mathrm{m}^{2}$ [mean \pm SD]) had an oral glucose tolerance test with $\mathrm{HbA}_{1 \mathrm{c}}, \mathrm{GA}$, and fructosamine assayed. These glycemic markers were repeated $11 \pm 7$ days later. Abnl-GT diagnosis required $0 \mathrm{~h} \geq 5.6 \mathrm{mmol} / \mathrm{L}$ ( $\geq 100 \mathrm{mg} / \mathrm{dL}$ ) and/or $2 \mathrm{~h} \geq 7.8 \mathrm{mmol} / \mathrm{L}\left(\geq 140 \mathrm{mg} / \mathrm{dL}\right.$ ). Thresholds for $\mathrm{HbA}_{1 \mathrm{c}}, \mathrm{GA}$, and fructosamine were the values at the 75th percentile for the population (39 mmol/ mol [5.7\%], $14.2 \%$, and $234 \mu \mathrm{mol} / \mathrm{L}$, respectively).

\section{RESULTS}

Abnl-GT prevalence in the nonobese was $34 \%$ versus $42 \%$ in the obese $(P=0.124)$. Reproducibility was excellent for $\mathrm{HbA}_{1 \mathrm{c}}$ and $\mathrm{GA}$ (both $\kappa \geq 0.8$ ), but moderate for fructosamine $\left(\kappa=0.6\right.$ ). Focusing on $\mathrm{HbA}_{1 \mathrm{c}}$ and $\mathrm{GA}$ in the nonobese, we found as single tests the sensitivities of $\mathrm{HbA}_{1 \mathrm{c}}$ and $\mathrm{GA}$ were $36 \%$ versus $37 \%(P=0.529)$. Combining $\mathrm{HbA}_{1 \mathrm{c}}$ and $\mathrm{GA}$, sensitivity increased to $58 \%$ because $\mathrm{GA}$ identified $37 \%$ of Africans with Abnl-GT not detected by $\mathrm{HbA}_{1 \mathrm{c}}\left(P\right.$ value for both tests vs. $\mathrm{HbA}_{1 \mathrm{c}}$ alone was $<0.001$ ). For the obese, sensitivities for $\mathrm{HbA}_{1 \mathrm{c}}, \mathrm{GA}$, and the combined tests were $60 \%, 27 \%$, and $67 \%$, respectively. Combined test sensitivity did not differ from $\mathrm{HbA}_{1 \mathrm{c}}$ alone $(P=0.25)$ because GA detected only $10 \%$ of obese Africans with Abnl-GT not detected by $\mathrm{HbA}_{1 \mathrm{c}}$.

\section{CONCLUSIONS}

Adding $\mathrm{GA}$ to $\mathrm{HbA}_{1 \mathrm{c}}$ improves detection of Abnl-GT in nonobese Africans.

Mathematical models predict that between 2019 and 2045, sub-Saharan Africa will experience a $143 \%$ increase in the prevalence of abnormal glucose tolerance (Abnl-GT) (1). This increase in Abnl-GT, which encompasses both prediabetes and type 2 diabetes (T2D), is the highest anticipated increase in the world (1). Slowing this upward trajectory requires strategies for the diagnosis of Abnl-GT that are feasible and effective in Africa.

Another challenge is that $60-80 \%$ of Africans living with Abnl-GT are undiagnosed (1). Hence, Africa has the highest prevalence in the world of people living with
Arsene F. Hobabagabo, ${ }^{1,2}$ Nana H. Osei-Tutu, ${ }^{1}$ Thomas Hormenu, ${ }^{1}$ Elyssa M. Shoup, ${ }^{1}$ Christopher W. DuBose, ${ }^{1}$ Lilian S. Mabundo, ${ }^{1}$ Joon $\mathrm{Ha}^{3}$ Arthur Sherman, ${ }^{3}$ Stephanie T. Chung, ${ }^{1}$ David B. Sacks, ${ }^{4}$ and Anne E. Sumner ${ }^{1,2}$
${ }^{1}$ Section on Ethnicity and Health, Diabetes, Endocrinology, and Obesity Branch, National Institute of Diabetes and Digestive and Kidney Diseases, National Institutes of Health, Bethesda, MD

${ }^{2}$ National Institute on Minority Health and Health Disparities, National Institutes of Health, Bethesda, MD

${ }^{3}$ Laboratory of Biological Modeling, National Institute of Diabetes and Digestive and Kidney Diseases, National Institutes of Health, Bethesda, MD

${ }^{4}$ National Institutes of Health Clinical Center, Bethesda, MD

Corresponding author:Anne E.Sumner, annes@ mail.nih.gov

Received 12 May 2020 and accepted 15 July 2020 Clinical trial reg. no. NCT00001853, clinicaltrials gov

This article contains supplementary material online at https://doi.org/10.2337/figshare.12690023.

A.F.H. and N.H.O.-T. are co-first authors.

(C) 2020 by the American Diabetes Association. Readers may use this article as long as the work is properly cited, the use is educational and not for profit, and the work is not altered. More information is available at https://www.diabetesjournals .org/content/license. 
undiagnosed Abnl-GT (1). Even when undetected, complications from Abnl-GT progress. Furthermore, Abnl-GT is associated with greater susceptibility and higher mortality from infectious diseases, including tuberculosis and coronavirus disease 2019 (2,3). Therefore, lowering the prevalence of Abnl-GT may assist in decreasing the scope and consequences of several important infectious diseases. However, the International Diabetes Federation reports that $<20 \%$ of African countries have in-country data on the prevalence of Abnl-GT (1).

The challenges of collecting data are magnified by the fact that routine tests used for Abnl-GT screening, such as fasting plasma glucose (FPG) and hemoglobin $A_{1 c}$ $\left(\mathrm{HbA}_{1 \mathrm{c}}\right)$, have poor diagnostic sensitivities ( $\leq 50 \%$ ) in Africans $(4,5)$. Thus, even when screening programs exist, Africans with Abnl-GT are often misdiagnosed as normal (6).

As a screening test, FPG is suboptimal. Fasting is difficult to achieve. People often travel many miles and wait for extended periods before being seen in clinics. In addition, people carry their food with them so they can easily eat when they are hungry. As going to a medical clinic and being fasted is not standard practice in many medical clinics in African countries, our focus is on the identification of effective nonfasting screening tests. Furthermore, blood samples kept at room temperature for even $30 \mathrm{~min}$ undergo extracorporeal glycolysis, resulting in the reporting of spuriously low glucose concentrations (7). $\mathrm{HbA}_{1 \mathrm{c}}$ is also problematic because, even in the absence of factors that adversely affect it, such as nutritional deficiencies, hemoglobinopathies, and anemia, $\mathrm{HbA}_{1 \mathrm{c}}$ detects $<50 \%$ of Africans with Abnl-GT (6). The diagnostic sensitivity of $\mathrm{HbA}_{1 \mathrm{c}}$ is also $<50 \%$ in African Americans, Whites, Hispanics, and Arab immigrants to the U.S. (8-10).

Due to the inadequate diagnostic performance of FPG and $\mathrm{HbA}_{1 \mathrm{c}}$, attention has turned to fructosamine and glycated albumin (GA), both of which are nonfasting markers of glycemia. Fructosamine reflects the concentration of all circulating glycated proteins, including $\mathrm{GA}$, which is formed by the nonenzymatic attachment of glucose to albumin (11).

A previous study of 236 African-born Blacks enrolled in the Africans in America study revealed that combining GA with $\mathrm{HbA}_{1 \mathrm{c}}$ doubled the detection of prediabetes in the nonobese (12). The prevalence of Abnl-GT in the nonobese needs special attention because in lowand middle-income countries globally and in Africa, the prevalence of T2D is rapidly rising in the nonobese $(1,13,14)$. To pursue improved detection of hyperglycemia in Africans, we increased recruitment to the Africans in America cohort and broadened our detection goal from prediabetes to Abnl-GT. With this larger cohort of 416 African-born Blacks living in America, our objectives were to determine by BMI category: 1) the prevalence of Abnl-GT, and 2) the diagnostic value and reproducibility of $\mathrm{HbA}_{1 \mathrm{c}}, \mathrm{GA}$, and fructosamine.

\section{RESEARCH DESIGN AND METHODS}

\section{Population}

The Africans in America cohort assesses the cardiometabolic health of Africanborn Blacks living in the U.S. $(15,16)$. Recruitment is by newspaper advertisements, flyers, community event presentations, and relevant websites. The National Institute of Diabetes and Digestive and Kidney Diseases (NIDDK) Institutional Review Board (ClinicalTrials .gov identifier NCT00001853; Bethesda, MD) approved the study. Written informed consent is obtained prior to enrollment.

During a telephone screening interview, potential enrollees must state they were born in sub-Saharan Africa to two Black parents who were also born in subSaharan Africa. Additionally, they must self-identify as healthy and deny a history of diabetes.

A total of 451 African-born Blacks living in metropolitan Washington, DC, successfully completed the telephone interview and had an outpatient screening visit at the National Institutes of Health (NIH) Clinical Center (Supplementary Fig. 1). A history, physical, electrocardiogram, and routine blood tests were performed. Thirty-three individuals did not proceed to an oral glucose tolerance test (OGTT). Exclusion criteria were: anemia $(n=10)$, elevated liver transaminases ( $n=1)$, hypothyroidism $(n=1)$, intravenous access issues $(n=4)$, and scheduling conflicts $(n=17)$. Two individuals were excluded after the OGTT because hemoglobin electrophoresis revealed hemoglobin type AF. The percent hemoglobin $\mathrm{F}$ in one participant was $15 \%$ and for the other person $25 \%$.
Hemoglobin $\mathrm{F}$ at these levels interferes with the determination of $\mathrm{HbA}_{1 \mathrm{c}}$ by the high-performance liquid chromatography (HPLC) used in this study.

\section{OGTTS}

OGTTs were performed in 416 individuals (male, 66\%; aged $39 \pm 10$ years [mean \pm $\mathrm{SD}$ ], range 20-65 years; BMI $27.7 \pm$ $4.5 \mathrm{~kg} / \mathrm{m}^{2}$, range $18.2-42.2 \mathrm{~kg} / \mathrm{m}^{2}$ ).

After a 12-h fast, participants came to the NIH Clinical Center at 7:00 A.M. On arrival, women provided a urine sample for pregnancy testing, and all were negative. As described previously, weight, height, and waist circumference (WC) were measured (15). Weight was obtained with a calibrated digital scale (Scale-Tronix 5702; Welch Allyn, Skaneateles Falls, NY). Height was measured with a wall stadiometer (Seca 242; Seca Corp., Hanover, MD). BMI was calculated as weight in kilograms divided by height in meters squared. BMI categories were defined according to World Health Organization guidelines (17). WC was measured at the superior border of the iliac crest at the end of expiration using a stretch-resistant tape measure with the person standing with feet hip-width apart and weight evenly distributed. The mean of three values was recorded.

Baseline blood samples were obtained for $\mathrm{HbA}_{1 \mathrm{c}}$, hemoglobin electrophoresis, glucose, insulin, GA, and fructosamine measurements. This was followed by an OGTT (TRUTOL 75 g; Custom Laboratories) with samples taken at $0.5,1$, and $2 \mathrm{~h}$ for glucose and insulin concentrations. Abnl-GT was defined as FPG $\geq 5.6 \mathrm{mmol} /$ $\mathrm{L}$ and/or 2-h glucose $\geq 7.8 \mathrm{mmol} / \mathrm{L}$ (1).

After the OGTT, a computed tomographic scan (Siemens and SOMATOM Force Scanner) was performed to measure visceral adipose tissue (VAT).

\section{Reproducibility of $\mathrm{HbA}_{1 \mathrm{c}}, \mathrm{GA}$, and Fructosamine Values}

To determine the reproducibility of $\mathrm{HbA}_{1 \mathrm{c}}$ $\mathrm{GA}$, and fructosamine, $36 \%$ (150 out of 416) of enrollees returned to the Clinical Center $11 \pm 7$ days after the OGTT.

Participants were divided into two groups (A and B) (Supplementary Fig. 1).

Group A comprised the first 281 consecutively enrolled individuals. In group $A$, repeat studies were planned only if the initial OGTT met the glucose criteria for T2D (1). Seventeen out of the 18 individuals newly diagnosed with $T 2 D$ returned 
for a second visit, and 1 declined. All 17 individuals had $\mathrm{HbA}_{1 \mathrm{c}}$ levels determined, but $G A$ and fructosamine concentrations were available only in the last 5 consecutively enrolled participants.

Group B consisted of the 135 subsequently enrolled individuals. All were invited, independent of glucose tolerance status at the initial OGTT, for a repeat study. Two individuals declined repeat studies. For one individual who did return, the blood sample obtained for $\mathrm{HbA}_{1 \mathrm{c}}$ clotted. Therefore, for group $\mathrm{B}$, duplicate $\mathrm{HbA}_{1 \mathrm{c}}, \mathrm{GA}$, and fructosamine were available for 132,133 , and 133 individuals, respectively.

Overall, repeat values were available for $\mathrm{HbA}_{1 \mathrm{c}}, \mathrm{GA}$, and fructosamine in 149 (17 plus 132), 138 (5 plus 133), and 138 (5 plus 133) individuals, respectively.

\section{Metabolic Parameters}

Degree of glycemia was measured by using the trapezoidal rule for area under the curve (AUC) for glucose during the OGTT. Insulin was assessed by the Matsuda Index, insulin secretion by AUC for insulin divided by AUC for glucose, and $\beta$-cell function by the Oral Disposition Index $(18,19)$.

\section{Assays}

Glucose and hs-CRP were measured in plasma and insulin in serum with a Roche Diagnostics cobas 6000 analyzer.

Hemoglobin, hematocrit, white blood cells, and mean corpuscular volume were measured in EDTA-anticoagulated whole blood using a Sysmex XE-5000.

\section{$\mathrm{HbA}_{1 \mathrm{c}}$ by HPLC}

$\mathrm{HbA}_{1 \mathrm{c}}$ values were determined with two different NGSP-certified instruments using HPLC technology manufactured by BioRad Laboratories. $\mathrm{HbA}_{1 \mathrm{c}}$ samples from the first 139 enrollees were measured on the VARIANT II instrument. The next 277 participants had $\mathrm{HbA}_{1 c}$ measurements performed on a D-10 instrument. The correlation $\left(R^{2}\right)$ and mean bias between the VARIANT II and D-10 instruments were 0.9934 and 0.07 (1.21\%), respectively.

\section{Fructosamine and GA}

Fructosamine and GA were measured in plasma on the cobas 6000 . For fructosamine, a colorimetric nitroblue tetrazolium assay was used. Interassay coefficient of variation for fructosamine was $2.9 \%$ at $308 \mu \mathrm{mol} / \mathrm{L}$ and $2.6 \%$ at $521 \mu \mathrm{mol} / \mathrm{L}$ (12). For GA, the Lucica GA-L enzymatic assay, provided by Asahi Kasei Pharma Corporation (Tokyo, Japan), was used. Albumin was measured with bromocresol purple. GA is reported as percent of albumin concentration. The interassay coefficient of variation for GA was $1.6 \%$ at $15.6 \%$ and $1.8 \%$ at $35.2 \%$.

\section{Determination of Diagnostic \\ Thresholds for $\mathrm{HbA}_{1 \mathrm{c}}, \mathrm{GA}$, and \\ Fructosamine}

For detecting Abnl-GT by $\mathrm{HbA}_{1 \mathrm{c}}$, the standard threshold of $39 \mathrm{mmol} / \mathrm{mol}(5.7 \%)$ was used (1). To identify a diagnostic threshold for GA and fructosamine, the procedure established by the Atherosclerosis Risk in Communities (ARIC) investigators was followed (20). As the diagnostic threshold for detecting Abnl-GT using $\mathrm{HbA}_{1 \mathrm{c}}$ was $39 \mathrm{mmol} / \mathrm{mol}$ (5.7\%) and corresponded to the upper quartile of our population distribution, we chose the upper quartile for GA (14.2\%) and fructosamine $(234 \mu \mathrm{mol} / \mathrm{L})$.

\section{Statistical Analyses}

Unless otherwise stated, data are presented as mean $\pm \mathrm{SD}$. Analyses included one-way ANOVA with Bonferroni corrections for multiple comparisons, $\chi^{2}$ tests, unpaired $t$ tests, McNemar test for matched pairs, Net Reclassification Improvement (NRI), and $\kappa$-statistic for diagnostic reproducibility. $\kappa$-Statistic categories were: slight $(0-0.20)$, fair $(0.21-0.40)$, moderate (0.41$0.60)$, substantial (0.61-0.80), and excellent (0.81-1.0) (21). $P$ values $\leq 0.05$ were considered significant. Analyses were performed with Stata 16.

\section{RESULTS}

The African regions of origin of the participants were: West $53 \%$ (220 out of 416 ), Central $18 \%$ ( 74 out of 416 ), and East 29\% (12 out of 416). Three participants from Southern African countries were included in the Central African group. Characteristics by African region of origin are provided in Supplementary Table 1. Of note, there was no difference by African region in sex distribution, age, or age at immigration. West Africans had resided in the U.S. the longest, $14 \pm 11$ years ( $P=$ 0.009 ). Hemoglobin did not differ by African region. The prevalence of heterozygous hemoglobinopathies (i.e., sickle cell trait and hemoglobin $C$ trait) were highest in West and Central Africa (both $P=0.002$ ).

There was no difference by African region in body size, glucose tolerance, insulin resistance, or insulin secretion (Supplementary Table 1). As these parameters did not vary significantly by African region of origin, participants from West, Central, and East Africa were combined into a single group and evaluated by BMI category and glucose tolerance status (Table 1).

\section{Metabolic Characteristics by BMI Category}

Seventy-five percent were nonobese (303 out of 416$)\left(\mathrm{BMI}<30 \mathrm{~kg} / \mathrm{m}^{2}\right)$ and $25 \%$ obese (113 out of 416$)\left(B M I \geq 30 \mathrm{~kg} / \mathrm{m}^{2}\right)$. The nonobese were younger than the obese participants ( $38 \pm 10$ vs. $41 \pm$ 10; $P=0.001)$. In addition, the nonobese had lower BMI, lower WC, and less VAT (Table 1). Raw data are presented in Table 1 ; even after adjustment for age, the significant differences between the nonobese and obese remained.

Additionally, FPG, 2-h glucose, and AUC-glucose were lower in the nonobese group. Similarly, the nonobese were less insulin resistant, had lower insulin secretion, and a higher Oral Disposition Index.

However, the prevalence of Abnl-GT (34\% vs. $42 \% ; P=0.124$ ) was similar in the nonobese and obese, respectively; and the absolute number of nonobese Africans with Abnl-GT ( $n=104)$ was nearly double the number of obese with Abnl-GT ( $n=48)$. Among the nonobese who had Abnl-GT, 30\% (31 out of 104) had a BMI $<25 \mathrm{~kg} / \mathrm{m}^{2}$, and $70 \%$ (73 out of 104) had a BMI $\geq 25.0 \mathrm{~kg} / \mathrm{m}^{2}$ and $<30 \mathrm{~kg} / \mathrm{m}^{2}$.

Reproducibility of Nonfasting Markers of Glycemia

Reproducibility by $\kappa$-statistic for $\mathrm{HbA}_{1 \mathrm{c}}$, $\mathrm{GA}$, and fructosamine was $0.85,0.83$, and 0.60 , respectively. This degree of reproducibility is excellent for $\mathrm{HbA}_{1 \mathrm{c}}$ and $\mathrm{GA}$, but only moderate for fructosamine (21). Therefore, only results for $\mathrm{HbA}_{1 \mathrm{c}}$ and $\mathrm{GA}$ are presented.

\section{$\mathrm{HbA}_{1 \mathrm{c}}$ and GA Individually and Combined}

The term GA-alone represents the added value provided by GA. Some case subjects with Abnl-GT were detected by $\mathrm{HbA}_{1 \mathrm{c}}$ and not GA (Fig. 1, in red). Some case subjects were detected by GA and not 
Table 1-Participant characteristics according to BMI category ${ }^{1}$

\begin{tabular}{|c|c|c|c|c|}
\hline Parameter $^{2}$ & Total $(n=416)$ & Nonobese $(n=303)(73 \%)$ & Obese $(n=113)(27 \%)$ & $P$ value ${ }^{3}$ \\
\hline Age (years) & $39 \pm 10$ & $38 \pm 10$ & $41 \pm 10$ & 0.001 \\
\hline $\mathrm{BMI}\left(\mathrm{kg} / \mathrm{m}^{2}\right)$ & $27.7 \pm 4.5$ & $25.5 \pm 2.7$ & $33.5 \pm 2.9$ & $<0.001$ \\
\hline BMI if Abnl-GT present $\left(\mathrm{kg} / \mathrm{m}^{2}\right)$ & $28.8 \pm 4.5$ & $26.3 \pm 2.3$ & $34.1 \pm 3.1$ & $<0.001$ \\
\hline WC $(\mathrm{cm})(n=415)$ & $91 \pm 12$ & $86 \pm 9$ & $103 \pm 9$ & $<0.001$ \\
\hline $\operatorname{VAT}\left(\mathrm{cm}^{3}\right)(n=406)$ & $99 \pm 69$ & $83 \pm 61$ & $143 \pm 71$ & $<0.001$ \\
\hline Fasting glucose (mmol/L) & $5.1 \pm 0.8$ & $5.1 \pm 0.5$ & $5.4 \pm 1.2$ & $<0.001$ \\
\hline Glucose at $2 \mathrm{~h}(\mathrm{mmol} / \mathrm{L})$ & $7.3 \pm 2.4$ & $7.1 \pm 2.1$ & $7.9 \pm 2.9$ & 0.001 \\
\hline AUC-glucose $(n=414)$ & $544 \pm 128$ & $533 \pm 109$ & $572 \pm 166$ & 0.007 \\
\hline ISI $(n=412)$ & $5.43 \pm 3.64$ & $6.01 \pm 3.73$ & $3.89 \pm 2.87$ & $<0.001$ \\
\hline Insulin secretion ( $n=412)$ & $0.54 \pm 0.36$ & $0.49 \pm 0.30$ & $0.67 \pm 0.45$ & $<0.001$ \\
\hline Oral Disposition Index $(n=412)$ & $2.25 \pm 0.99$ & $2.34 \pm 0.98$ & $2.01 \pm 0.97$ & 0.002 \\
\hline Abnl-GT (\%) & $37(152 / 416)$ & $34(104 / 303)$ & $42(48 / 113)$ & 0.124 \\
\hline Diabetes (\%) & $7(28 / 416)$ & $5(16 / 303)$ & $11(12 / 113)$ & 0.053 \\
\hline Prediabetes $(\%)^{4}$ & $32(124 / 388)$ & $31(88 / 287)$ & $36(36 / 101)$ & 0.356 \\
\hline
\end{tabular}

${ }^{1}$ Nonobese: $\mathrm{BMI}<30.0 \mathrm{~kg} / \mathrm{m}^{2}$; obese: $\mathrm{BMI} \geq 30.0 \mathrm{~kg} / \mathrm{m}^{2}$. ${ }^{2}$ Data are mean $\pm \mathrm{SD}$ or percentages. ${ }^{3}$ Comparisons were by unpaired $t$ tests for continuous variables and $\chi^{2}$ for categorical variables. ${ }^{4}$ Denominators are all individuals without diabetes (normal glucose tolerance and prediabetes).

$\mathrm{HbA}_{1 \mathrm{c}}$ (Fig. 1, in blue). Some were identified by both tests (Fig. 1, in purple). GA-alone refers to the individuals with Abnl-GT detected by $\mathrm{GA}$ and not $\mathrm{HbA}_{1 \mathrm{c}}$ (Fig. 1, in blue).

\section{Sensitivities and Specificities}

\section{Nonobese}

Sensitivity for the diagnosis of Abnl-GT by $\mathrm{HbA}_{1 \mathrm{c}}$ and $\mathrm{GA}$ was similar, $36 \%$ and $37 \%$, respectively ( $P=0.999)$. The sensitivity of the combined tests was $58 \%$, which was significantly greater than $\mathrm{HbA}_{1 \mathrm{c}}$ alone $(P<0.001)$ (Fig. $2 A$ and Supplementary Table 2). Sensitivity was higher for the combined tests because GA-alone identified $37 \%$ ( 22 out of 60 ) of the nonobese not detected by $\mathrm{HbA}_{1 \mathrm{c}}$
(Fig. 1). Specificities for the diagnosis of Abnl-GT singly by $\mathrm{HbA}_{1 \mathrm{c}}$ and by $\mathrm{GA}$ and then both combined were $80 \%, 75 \%$, and $60 \%$, respectively (Supplementary Table 2). The NRI for $\mathrm{HbA}_{1 \mathrm{c}}$ plus $\mathrm{GA}$ versus $\mathrm{HbA}_{1 \mathrm{c}}$ alone was $0.238(95 \% \mathrm{Cl} 0.018$, $0.459 ; P=0.034$ ).

\section{Obese}

For the diagnosis of Abnl-GT, the sensitivity of $\mathrm{HbA}_{1 \mathrm{c}}$ at $60 \%$ was greater than the sensitivity of $27 \%$ for GA $(P<0.001)$. As GA-alone detected only $10 \%$ (3 out of 32 ) of the obese not detected by $\mathrm{HbA}_{1 \mathrm{c}}$, combining $\mathrm{HbA}_{1 \mathrm{c}}$ with $\mathrm{GA}$ did not improve detection of Abnl-GT $(P=0.250)$ (Fig. $2 B$ and Supplementary Table 2). Specificities for the diagnosis of Abnl-GT by $\mathrm{HbA}_{1 \mathrm{c}}$ and $\mathrm{GA}$ singly and combined

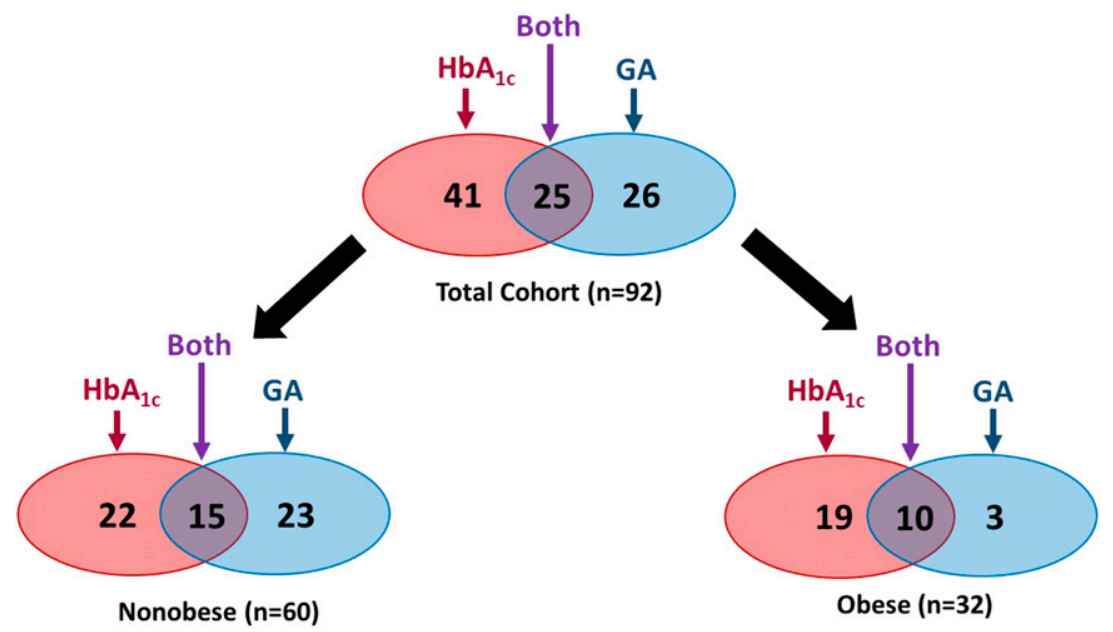

Figure 1-Successful diagnostic test by BMI category in participants with Abnl-GT. The diagnostic color coding: red for $\mathrm{HbA}_{1 \mathrm{c}}$, blue for $\mathrm{GA}$, and purple for both tests.

were: $80 \%, 94 \%$, and $74 \%$, respectively (Supplementary Table 2). The NRI for $\mathrm{HbA}_{1 \mathrm{c}}$ versus $\mathrm{GA}$ versus $\mathrm{HbA}_{1 \mathrm{c}}$ alone was $0.419(95 \% \mathrm{Cl} 0.141,0.696 ; P=$ 0.003).

\section{Total Cohort}

Diagnostic sensitivities of $\mathrm{HbA}_{1 \mathrm{c}}$ and GA were $43 \%$ versus $34 \%(P=0.086)$. At $61 \%$, the sensitivity of the combined tests was significantly greater than when only $\mathrm{HbA}_{1 \mathrm{c}}$ was used $(P<0.001)$ (Fig. $2 C$ and Supplementary Table 2). By identifying $28 \%$ (26 out of 92) of Africans with Abnl-GT not detected by $\mathrm{HbA}_{1 \mathrm{c}}$, $\mathrm{GA}$-alone contributed to the higher sensitivity of the combined tests in the nonobese category. Specificities for the diagnosis of Abnl-GT by $\mathrm{HbA}_{1 \mathrm{c}}$ and $\mathrm{GA}$ singly and combined were $80 \%, 80 \%$, and $63 \%$, respectively (Supplementary Table 2). The NRI for $\mathrm{HbA}_{1 \mathrm{c}}$ and $\mathrm{GA}$ versus $\mathrm{HbA}_{1 \mathrm{c}}$ alone was $0.270(95 \% \mathrm{Cl} 0.091,0.448$; $P=0.003)$.

Characteristics of Individuals With Abnl-GT Diagnosed by $\mathrm{GA}$-Alone Versus $\mathrm{HbA}_{1 \mathrm{c}}$ Participants with Abnl-GT detected by GA-alone were younger than those detected by $\mathrm{HbA}_{1 \mathrm{c}}$ ( $41 \pm 9$ vs $47 \pm 10$ years; $P=0.015)$. BMI, WC, and VAT were also lower (Fig. 3). Differences in body size did not change with age adjustment; therefore, raw data are presented (Fig. 3 and Supplementary Table 3). In contrast to body size measurements, insulin resistance, insulin secretion, and Disposition Index did not differ by diagnostic test (Supplementary Table 3). Similarly, prevalence of heterozygous hemoglobinopathy 

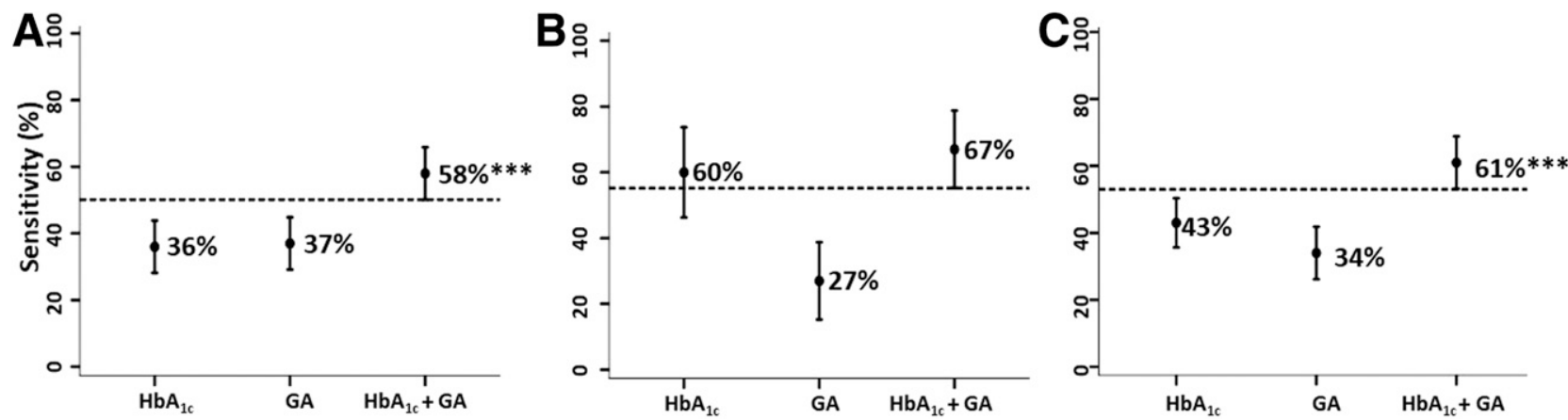

Figure 2-Sensitivities for the diagnosis of Abnl-GT by BMI category for $\mathrm{HbA}_{1 \mathrm{c}}$ and $\mathrm{GA}$ singly and combined. $A$ : Nonobese: sensitivities for $\mathrm{HbA}$, $36 \%$; GA, 37\%; and $\mathrm{HbA}_{1 \mathrm{c}}$ plus GA, 58\%. Corresponding specificities were $80 \%, 75 \%$, and $60 \%$, respectively. $B$ : Obese: sensitivities for $\mathrm{HbA}$ c, $60 \%$; $\mathrm{GA}$, $27 \%$; and $\mathrm{HbA}_{1 \mathrm{c}}$ plus $\mathrm{GA}, 67 \%$. Corresponding specificities were $80 \%, 94 \%$, and $74 \%$, respectively. C: Whole cohort: sensitivities for $\mathrm{HbA} \mathrm{Ac}_{1 \mathrm{c}}, 43 \%$; $\mathrm{GA}, 34 \%$; and $\mathrm{HbA}_{1 \mathrm{c}}$ plus GA, 61\%. Corresponding specificities were $80 \%, 80 \%$, and $63 \%$, respectively. Data are mean $(95 \% \mathrm{Cl})$. $* * * P<0.001$.

(sickle cell trait or hemoglobin C trait) ( $27 \%$ vs. $24 \% ; P=0.789$ ) and albumin $(4.04 \pm 0.25$ vs. $3.98 \pm 0.28 ; P=$ $0.367)$ did not differ by diagnostic test (Supplementary Table 3).

\section{CONCLUSIONS}

This investigation made three findings that could influence the approach to Abnl-GT in Africa. First, there were significant differences by BMI category in the diagnostic capabilities of GA and $\mathrm{HbA}_{1 \mathrm{c}}$ such that the combination leads to improved detection of Abnl-GT in the nonobese. Second, the prevalence of Abnl-GT was similar in nonobese and obese Africans. Third, in contrast to fructosamine, both $\mathrm{HbA}_{1 \mathrm{c}}$ and $\mathrm{GA}$ provided highly reproducible results.

Overall, the combination of GA and $\mathrm{HbA}_{1 \mathrm{c}}$ identified more Africans with Abnl-GT than $\mathrm{HbA}_{1 \mathrm{c}}$. This was because $\mathrm{GA}$ increased detection of the nonobese with Abnl-GT by $33 \%$ (Fig. 1). As adding GA did not improve the detection of Abnl-GT in the obese, the use of GA could be reserved for the nonobese.
The prevalence of Abnl-GT in African immigrants to the U.S. was $37 \%$ and similar in the nonobese and obese. Therefore, clinicians caring for Africans should not identify an individual as "low risk" because they are nonobese $(15,22)$. In short, the threshold for BMI-related risk for Abnl-GT may be lower in Africans than for African Americans, which suggests the need for tailored therapeutic approaches (23). Furthermore, Abnl-GT in the nonobese is observed in India and in many other low- and middle-income countries globally $(13,14)$.

Reproducibility of diagnostic markers is another important finding. With studies done $11 \pm 7$ days apart and $а$ K-statistic $\geq 0.8$ for both $\mathrm{HbA}_{1 \mathrm{c}}$ and $\mathrm{GA}$, their reproducibility was excellent. Hence, the biological variability and the interassay variation for both $\mathrm{HbA}_{1 \mathrm{c}}$ and $\mathrm{GA}$ are low. In contrast, the fructosamine assay is less optimal and subject to more analytic variables than GA (24). Therefore, it is not surprising that duplicate fructosamine studies revealed only moderate reproducibility ( $\kappa$-statistic of 0.6 ). Suboptimal
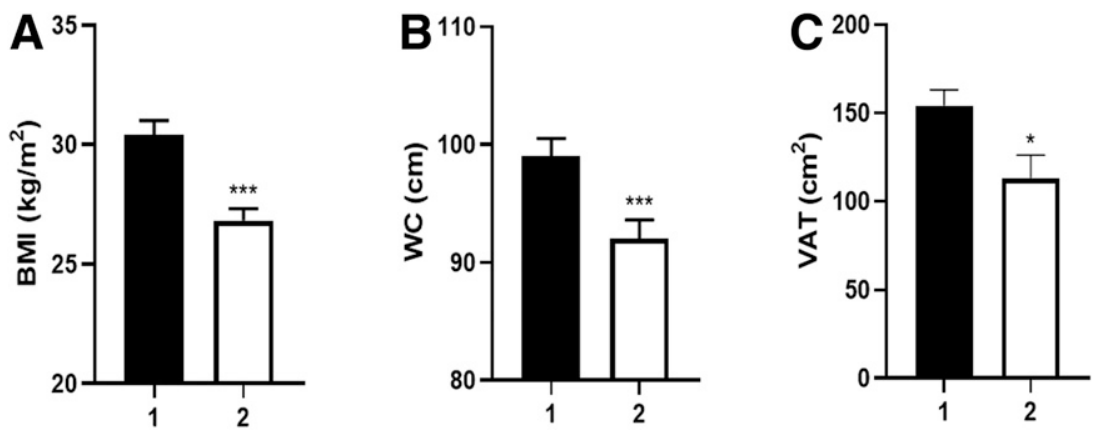

Figure 3-Participant characteristics with Abnl-GT according to diagnostic test: $A$ : BMI, $B$ : WC, $C$ : VAT. In each panel: 1 is $\mathrm{HbA}_{1 \mathrm{c}}$ or $\mathrm{HbA}_{1 \mathrm{c}}$ and $\mathrm{GA} ; 2$ is $\mathrm{GA}$-alone. Data presented as mean $\pm \mathrm{SE}$. $* P<0.05 ; * * * P<0.001$. reproducibility may explain why for Abnl$\mathrm{GT}$, fructosamine is a poor diagnostic test (25).

Relationship Between GA and BMI Africans with Abnl-GT detected by GA-alone had lower BMI, WC, and VAT than their counterparts detected by $\mathrm{HbA}_{1 \mathrm{c}}$ (Fig. 3). This is consistent with the observation that GA correlates inversely with $\mathrm{BMI}$, WC, and VAT $(12,26)$. In fact, He et al. (27) found that for every $1 \mathrm{~kg} / \mathrm{m}^{2}$ increase in $\mathrm{BMI}, \mathrm{GA}$ decreased by $0.13 \%$. This inverse relationship is often attributed to increased catabolism of albumin from obesity-related chronic inflammation or insulin resistance $(28,29)$. Interestingly, degree of insulin resistance and $\beta$-cell function did not differ by diagnostic test (Supplementary Table 3). Therefore, the etiology of Abnl-GT (insulin resistance vs. relative $\beta$-cell failure) cannot be ascertained by whether diagnosis was by $\mathrm{HbA}_{1 \mathrm{c}}$ or $\mathrm{GA}$.

\section{BMI Category to Guide Use of GA}

In detecting Abnl-GT, the diagnostic utility of GA appears to depend on BMI category. We speculate that for normal-weight people, GA-alone may be sufficient to detect Abnl-GT. In overweight people, $\mathrm{GA}$ should be combined with $\mathrm{HbA}_{1 \mathrm{c}}$, while $\mathrm{HbA}_{1 \mathrm{c}}$ may be satisfactory in obese people.

Studies from East Asia reveal that the performance of GA as a single diagnostic test was equivalent to or better than $\mathrm{HbA}_{1 c}$ $(30,31)$. GA may be an effective diagnostic test for Abnl-GT because the BMI in East Asians with T2D is typically $<25 \mathrm{~kg} /$ $\mathrm{m}^{2}$ (31).

In the Africans in America cohort, twothirds of the nonobese participants with 
Abnl-GT were overweight (BMI 25.0$\left.29.9 \mathrm{~kg} / \mathrm{m}^{2}\right)$, and one-third were normal weight $\left(<25.0 \mathrm{~kg} / \mathrm{m}^{2}\right)$. Considering that the Africans in America cohort represents mainly the overweight with Abnl-GT, we found that combining $\mathrm{HbA}_{1 \mathrm{c}}$ with $\mathrm{GA}$ optimized detection.

For obese people with Abnl-GT, $\mathrm{HbA}_{1 c}$ alone may be sufficient. In a South African study of mixed-ancestry adults in whom the mean BMI of the group with T2D was $32.5 \mathrm{~kg} / \mathrm{m}^{2}$, Zemlin et al. (32) reported that the combination of $\mathrm{GA}$ and $\mathrm{HbA}_{1 \mathrm{c}}$ was no better than $\mathrm{HbA}_{1 \mathrm{c}}$ alone. Our findings were similar in the obese participants in the Africans in America cohort (Fig. 2B). However, NRI suggests that the combined tests may be beneficial in the obese as well (Supplementary Table 4). While this would be an excellent development, there is concern that the assumptions made in the calculation of NRI may be overly optimistic in predicting improvement (33).

\section{Feasibility of Obtaining GA}

The enzymatic method used to measure GA has been evaluated in many clinical studies and is approved for use in the U.S., Japan, Korea, Indonesia, and China $(11,30)$. The assay is reproducible, precise, and easily performed on automated analyzers that can measure glucose or electrolytes. Analyzers of this type are widely available in both clinical and research settings in Africa (M. Nyirenda, personal communication).

\section{Methodology for Determining Diagnostic Thresholds for GA}

Thresholds for FPG, 2-h glucose, and $\mathrm{HbA}_{1 \mathrm{c}}$ were determined by their relationship to diabetic retinopathy (34). The methods used to determine diagnostic thresholds for GA rely on glucose concentrations obtained during the OGTT. The two most common approaches are: 1) identifying the ability of GA to predict Abnl-GT by calculating the area under the receiver operating characteristic curve and applying the Youden Index to define the optimal cut point (30-32), and 2) use the GA cutoff at the upper 75th, 95th, or 97.5th percentile of the population being evaluated (20). For example, the ARIC investigators determined the upper fraction of their cohort who had $\mathrm{HbA}_{1 \mathrm{c}} \geq 5.7 \%$. As $5.7 \%$ occurred as the cutoff for the 75 th percentile, they used the GA threshold at the 75th percentile
(20). With these two approaches, GA thresholds range from 13 to $16 \%$ depending on whether the outcome is prediabetes, T2D, or a combination (i.e., Abnl-GT) $(20,30-32)$. We used the approach taken by the ARIC investigators, and our threshold for Abnl-GT was $14.2 \%$.

To systematically resolve which diagnostic threshold to use for GA, the way forward may be a two-step process with the establishment of an International Working Group followed by an International Consensus Panel. The International Working Group could survey existing studies and determine: 1) end point criteria for GA (retinopathy or glucose or other), 2) the statistical methodology for determining threshold (AUC-receiver operating characteristic or percentile), and 3) size and diversity of the cohorts needed to test recommendations. Within these cohorts, BMI and race/ethnicity would be specifically considered. If the International Working Group decides that current data are insufficient, parameters for study design for future determination by International Consensus Panel could be set.

\section{Strengths and Limitations}

Our study is the largest exploring the diagnostic value of nonfasting markers of glycemia in African-born Blacks. In addition, it is the first investigation to explore the diagnostic reproducibility of $\mathrm{GA}$, fructosamine, and $\mathrm{HbA}_{1 \mathrm{c}}$. Furthermore, studies evaluating the diagnostic efficacy of these markers often state they cannot rule out the effect of confounding factors (6). However, our study provides documentation of the performance of $\mathrm{GA}$, fructosamine, and $\mathrm{HbA}_{1 \mathrm{c}}$ in the absence of cirrhosis, thyroid disease, hemoglobinopathies, anemia, nutritional deficiencies, hypoalbuminemia, and renal failure.

The study used a convenience sample. However, for three reasons, the Africans in America cohort appears to be representative of African-born Blacks living in the U.S. First, as most participants were from West African countries, the sample size of 416 was large enough to reflect known immigration patterns (35). Second, compared with East Africa, the prevalence of sickle cell trait and hemoglobin $C$ trait was higher in West and Central Africans. Therefore, the sample size was large enough to detect known genetic differences by African region of origin (36). Third, the prevalence of T2D was $7 \%$, which was comparable to the $8 \%$ prevalence of T2D in African-born Blacks living in Canada (37). Similar data are not available in the U.S.

The potential limitations of our investigation are intrinsic to our study design. One limitation is the applicability of our results to populations in African countries. However, we designed the study to use resources available in America to provide a proof of concept about the potential value of GA in Africans. Therefore, our investigation provides justification: 1) for the funding of studies to be conducted in Africa, and 2) for the study to be used for power analyses for population-based prospective studies that have optimization of $\mathrm{GA}$ and $\mathrm{HbA}_{1 \mathrm{c}}$ thresholds built into their study design. To assist in these analyses, we provided the total number of participants with Abnl-GT and then for the two components of Abnl-GT, diabetes and prediabetes (Table 1). The current study was not large enough to examine diabetes and prediabetes separately.

Another challenge for African countries is that in the absence of point-of-care options for GA, initial studies will have to be conducted in urban or semiurban areas where there is access to clinics that have both automated analyzers and the opportunity to detect confounders such as nutritional deficiencies, infections, and hemoglobinopathies.

In addition, we focused on sensitivity over specificity. Results for specificity for each testing paradigm are provided only in the legend to Fig. 2 and Supplementary Table 2. However, the sensitivity of $\mathrm{HbA}_{1 \mathrm{c}}$ as a single test in the nonobese is $<40 \%$. Therefore, $\mathrm{HbA}_{1 \mathrm{c}}$ is not a viable option for effective screening for a disease that is reaching epidemic proportions in Africa. After improved detection is achieved, future studies can determine if the benefits of more optimal detection offset the lower specificity.

\section{Conclusion}

Between 2019 and 2045, a steep increase in Abnl-GT prevalence in Africa, especially in the nonobese, is anticipated. Innovative and improved diagnostic tools may be the best way to limit the epidemic, improve data collection, and inform treatment paradigms. GA is a nonfasting, easily obtainable, highly reproducible test that, in combination with $\mathrm{HbA}_{10}$ provides valuable 
diagnostic information about Abnl-GT in nonobese Africans living in the U.S. Data from the Africans in America cohort provide a proof of concept and can serve as primary data for sample size calculations for population-based prospective studies in Africa. Research on the diagnostic value of GA may lead to better screening, earlier interventions, and ultimately less medical and social consequences from Abnl-GT.

Acknowledgments. The authors thank Paulina Stallcup, Clinical Center, National Institutes of Health, Bethesda, MD, for the laboratory expertise, commitment, and time.

Funding. The study was funded by the intramural research program of two NIH institutes, NIDDK and National Institute on Minority Health and Health Disparities (NIMHD), and the NIH Clinical Center. A.F.H. and A.E.S. are supported by the intramural programs of both NIDDK and NIMHD. N.H.O.-T., T.H., E.M.S., C.W.D., L.S.M., J.H., A.S., and S.T.C. are supported by the intramural program of NIDDK. D.B.S. is supported by the NIH Clinical Center.

Duality of Interest. No potential conflicts of interest relevant to this article were reported. Author Contributions. A.F.H., N.H.O.-T., and A.E.S. did the literature search. D.B.S. and A.E.S. designed the study. A.F.H., N.H.O.-T., T.H., E.M.S., C.W.D., L.S.M., and A.E.S. contributed to enrollment. A.F.H., N.H.O.-T., T.H., E.M.S., C.W.D., L.S.M., S.T.C., and A.E.S. collected the data. A.F.H., N.H.O.-T., T.H., E.M.S., J.H., A.S., S.T.C., D.B.S., and A.E.S. analyzed the data. A.F.H., N.H.O.-T., and A.E.S. made the figures. A.F.H., N.H.O.-T., E.M.S., and A.E.S. made the tables. A.F.H., N.H.O.-T., and A.E.S. wrote the first draft. A.F.H., N.H.O.-T., T.H., E.M.S., C.W.D., L.S.M., J.H., A.S., S.T.C., D.B.S., and A.E.S. provided critical rewrites of the manuscript. A.E.S. is the guarantor of this work and, as such, had full access to all of the data in the study and takes responsibility for the integrity of the data and the accuracy of the data analysis.

Prior Presentation. This study was presented in abstract form at the 79th Scientific Sessions of the American Diabetes Association, San Francisco, CA, 7-11 June 2019.

\section{References}

1. International Diabetes Federation. IDF Diabetes Atlas, 9th edition, 2019. Accessed 5 May 2020. Available from https://diabetesatlas.org 2. Al-Rifai RH, Pearson F, Critchley JA, AbuRaddad $\amalg$. Association between diabetes mellitus and active tuberculosis: a systematic review and meta-analysis. PLoS One 2017;12:e0187967 3. Muniyappa R, Gubbi S. COVID-19 pandemic, coronaviruses, and diabetes mellitus. Am J Physiol Endocrinol Metab 2020;318:E736-E741

4. Kengne AP, Erasmus RT, Levitt NS, Matsha TE. Alternative indices of glucose homeostasis as biochemical diagnostic tests for abnormal glucose tolerance in an African setting. Prim Care Diabetes 2017;11:119-131

5. Sumner AE, Thoreson CK, O'Connor MY, et al. Detection of abnormal glucose tolerance in
Africans is improved by combining $\mathrm{A} 1 \mathrm{C}$ with fasting glucose: the Africans in America Study. Diabetes Care 2015;38:213-219

6. Briker SM, Aduwo JY, Mugeni R, et al. A1C underperforms as a diagnostic test in Africans even in the absence of nutritional deficiencies, anemia and hemoglobinopathies: insight from the Africans in America study. Front Endocrinol (Lausanne) 2019;10:533

7. Sacks DB. A1C versus glucose testing: a comparison. Diabetes Care 2011;34:518-523

8. Lorenzo C, Wagenknecht LE, Hanley AJ, Rewers MJ, Karter AJ, Haffner SM. A1C between 5.7 and $6.4 \%$ as a marker for identifying pre-diabetes, insulin sensitivity and secretion, and cardiovascular risk factors: the Insulin Resistance Atherosclerosis Study (IRAS). Diabetes Care 2010;33:2104-2109

9. Olson DE, Rhee MK, Herrick K, Ziemer DC, TwomblyJG, Phillips LS. Screening for diabetes and pre-diabetes with proposed A1C-based diagnostic criteria. Diabetes Care 2010;33:2184-2189

10. Pinelli NR, Jantz AS, Martin ET, Jaber LA. Sensitivity and specificity of glycated hemoglobin as a diagnostic test for diabetes and prediabetes in Arabs. J Clin Endocrinol Metab 2011; 96:E1680-E1683

11. Welsh KJ, Kirkman MS, Sacks DB. Role of glycated proteins in the diagnosis and management of diabetes: research gaps and future directions. Diabetes Care 2016;39:1299-1306

12. Sumner $A E$, Duong MT, Bingham BA, et al. Glycated albumin identifies prediabetes not detected by hemoglobin A1c: the Africans in America study. Clin Chem 2016;62:1524-1532

13. Dagenais GR, Gerstein HC, Zhang X, et al. Variations in diabetes prevalence in low-, middle-, and high-income countries: results from the prospective urban and rural epidemiological study. Diabetes Care 2016;39:780-787

14. Staimez LR, Deepa M, Ali MK, Mohan V, Hanson RL, Narayan KMV. Tale of two Indians: heterogeneity in type 2 diabetes pathophysiology. Diabetes Metab Res Rev 2019;35:e3192

15. Kabakambira JD, Baker RL Jr., Briker SM, et al. Do current guidelines for waist circumference apply to black Africans? Prediction of insulin resistance by waist circumference among Africans living in America. BMJ Glob Health 2018;3:e001057

16. O'Connor MY, Thoreson CK, Ricks M, et al. Worse cardiometabolic health in African immigrant men than African American men: reconsideration of the healthy immigrant effect. Metab Syndr Relat Disord 2014;12:347-353

17. World Health Organization. Obesity and Overweight [Fact Sheet], 2020. Accessed 13 July 2020. Available from https://www.who.int/news-room/ fact-sheets/detail/obesity-and-overweight

18. Jagannathan R, Sevick MA, Li H, et al. Elevated 1-hour plasmaglucose levels are associated with dysglycemia, impaired beta-cell function, and insulin sensitivity: a pilot study from a real world health care setting. Endocrine 2016;52:172-175 19. Matsuda M, DeFronzo RA. Insulin sensitivity indices obtained from oral glucose tolerance testing: comparison with the euglycemic insulin clamp. Diabetes Care 1999;22:1462-1470

20. Selvin $E$, Rawlings AM, Grams $M$, et al. Fructosamine and glycated albumin for risk stratification and prediction of incident diabetes and microvascular complications: a prospective cohort analysis of the Atherosclerosis Risk in Communities (ARIC) study. Lancet Diabetes Endocrinol 2014;2:279-288
21. Khan KS, Chien PF. Evaluation of a clinical test. I: assessment of reliability. BJOG 2001;108:562-567 22. Ekoru K, Murphy GAV, Young EH, et al. Deriving an optimal threshold of waist circumference for detecting cardiometabolic risk in sub-Saharan Africa. Int J Obes (Lond) 2017;42:487-494

23. Utumatwishima JN, Chung ST, Bentley AR, Udahogora M, Sumner AE. Reversing the tide diagnosis and prevention of T2DM in populations of African descent. Nat Rev Endocrinol 2018;14:45-56 24. Danese E, Montagnana M, Nouvenne A, Lippi G. Advantages and pitfalls of fructosamine and glycated albumin in the diagnosis and treatment of diabetes. J Diabetes Sci Technol 2015;9:169-176 25. Shima K, Abe F, Chikakiyo H, Ito N. The relative value of glycated albumin, hemoglobin A1c and fructosamine when screening for diabetes mellitus. Diabetes Res Clin Pract 1989;7:243-250

26. Wang $F, M a X$, Hao $Y$, et al. Serum glycated albumin is inversely influenced by fat mass and visceral adipose tissue in Chinese with normal glucose tolerance. PLoS One 2012;7:e51098

27. He X, Mo Y, Ma X, et al. Associations of body mass index with glycated albumin and glycated albumin/glycated hemoglobin $A_{1 c}$ ratio in Chinese diabetic and non-diabetic populations. Clin Chim Acta 2018;484:117-121

28. Koga M, Hirata T, Kasayama S, Ishizaka $Y$, Yamakado M. Body mass index negatively regulates glycated albumin through insulin secretion in patients with type 2 diabetes mellitus. Clin Chim Acta 2015;438:19-23

29. Miyashita $Y$, Nishimura $R$, Morimoto $A$, Matsudaira T, Sano H, Tajima N. Glycated albumin is low in obese, type 2 diabetic patients. Diabetes Res Clin Pract 2007;78:51-55

30. Hsu P, Ai M, Kanda E, et al. A comparison of glycated albumin and glycosylated hemoglobin for the screening of diabetes mellitus in Taiwan. Atherosclerosis 2015;242:327-333

31. Ikezaki H, Furusyo N, Ihara T, et al. Glycated albumin as a diagnostic tool for diabetes in a general Japanese population. Metabolism 2015;64:698-705 32. Zemlin $A E$, Barkhuizen $M$, Kengne $A P$, Erasmus RT, Matsha TE. Performance of glycated albumin for type 2 diabetes and prediabetes diagnosis in a South African population. Clin Chim Acta 2019;488:122-128

33. Pepe MS, Fan J, Feng Z, Gerds T, Hilden J. The Net Reclassification Index (NRI): a misleading measure of prediction improvement even with independent test data sets. Stat Biosci 2015;7: 282-295

34. Colagiuri S, Lee CM, Wong TY, Balkau B, Shaw JE, Borch-Johnsen K; DETECT-2 Collaboration Writing Group. Glycemic thresholds for diabetes-specific retinopathy: implications for diagnostic criteria for diabetes. Diabetes Care 2011; 34:145-150

35. Gambino CP, Trevelyan EN, Fitzwater JT. The Foreign-Born Population from Africa: 2008-2012. Accessed 5 May 2020. Available from https://www .census.gov/library/publications/2014/acs/acsbr1216.html

36. Piel FB, Patil AP, Howes RE, et al. Global epidemiology of sickle haemoglobin in neonates: a contemporary geostatistical model-based map and population estimates. Lancet 2013;381:142-151

37. Creatore MI, Moineddin R, Booth G, et al. Age- and sex-related prevalence of diabetes mellitus among immigrants to Ontario, Canada. CMAJ 2010;182:781-789 